\title{
Characterization of sperm surface and seminal plasma glycoproteins of the chimpanzee
}

\author{
G. E. Olson and K. G. Gould \\ Department of Anatomy, Vanderbilt University, Nashville, Tennessee 37232, and Yerkes \\ Regional Primate Research Center, Emory University, Atlanta, Georgia 30322, U.S.A.
}

\begin{abstract}
Summary. Washed ejaculated chimpanzee spermatozoa and a $100000 \mathrm{~g}$ supernatant of seminal plasma were subjected to radiolabelling by sequential treatment with galactose oxidase and sodium boro $\left[{ }^{3} \mathrm{H}\right]$ hydride or with sodium metaperiodate and $\mathrm{NaB}^{3} \mathrm{H}_{4}$. Sperm surface glycoproteins and seminal plasma glycoproteins radiolabelled by these procedures were compared by SDS-polyacrylamide gel electrophoresis. Spermatozoa labelled by galactose oxidase treatment showed a single labelled macromolecular component of 37000 whereas spermatozoa labelled by sodium metaperiodate- $\mathrm{NaB}^{3} \mathrm{H}_{4}$ treatment showed incorporation into macromolecular components of 37000 and 25000 mol. wt. Seminal plasma radiolabelled by galactose oxidase- $\mathrm{NaB}^{3} \mathrm{H}_{4}$ treatment contained labelled components of $47000,37000,19000$ and 12000 mol. wt, whereas seminal plasma radiolabelled with sodium metaperiodate- $\mathrm{NaB}^{3} \mathrm{H}_{4}$ contained macromolecular components of 47000,37000 , and 19000 mol. wt.
\end{abstract}

\section{Introduction}

The surface of mammalian spermatozoa undergoes progressive modification during posttesticular development. These modifications occur during sperm passage through the excurrent duct system of the male tract, after ejaculation due to interaction of spermatozoa with seminal plasma components and during sperm residence in the female tract (Bedford, 1975; Orgebin-Crist, Danzo \& Davies, 1975; Bedford \& Cooper, 1978, for reviews). The interaction of secretory products of the excurrent duct system and accessory glands with the sperm plasma membrane has been demonstrated by various immunological, biochemical and histochemical techniques (Hunter, 1969; Barker \& Amann, 1971; Killian \& Amann, 1973; Gordon, Dandekar \& Bartoszewicz, 1975; Nicolson, Usui, Yanagimachi, Yanagimachi \& Smith, 1977; Lea, Petrusz \& French, 1978; Voglmayr, Fairbanks, Jackowitz \& Colella, 1980). It is believed that these changes may be of significance for sperm maturation which occurs in the epididymis and for capacitation which occurs in the female tract. However, in many instances a characterization of the components binding to the surface of the spermatozoon has not been reported.

The present study was undertaken to provide data upon the potential modification of the sperm surface by seminal plasma constituents. We report here data obtained from radiolabelling experiments designed to identify macromolecular surface components of chimpanzee spermatozoa. The same techniques were employed to identify glycoprotein components of seminal plasma for subsequent comparison of the seminal plasma and sperm surface components. 


\section{Materials and Methods}

Ejaculates were obtained from adult chimpanzees. Semen from 6 different animals was used in the present study; up to 4 samples were obtained from some animals to monitor consistency of the results. Semen was allowed to liquefy at $37^{\circ} \mathrm{C}$ and the liquid fraction was centrifuged at $500 \mathrm{~g}$ for $15 \mathrm{~min}$. The sperm pellet and supernatant were then separated. The sperm pellet was immediately used in the radiolabelling procedures described below while the supernatant fraction was frozen and stored at $-70^{\circ} \mathrm{C}$ until used.

The sperm pellet was resuspended in phosphate-buffered saline (PBS $=0.145 \mathrm{M}-\mathrm{NaCl}$ and $0.01 \mathrm{M}$-sodium phosphate, $\mathrm{pH} 7.1$ ) and again centrifuged at $500 \mathrm{~g}$ for $10 \mathrm{~min}$. The resulting sperm pellet was gently suspended with $2 \mathrm{ml}$ PBS and divided into two equal aliquots. One aliquot was radiolabelled by galactose oxidase-sodium boro $\left[{ }^{3} \mathrm{H}\right]$ hydride $\left(\mathrm{NaB}^{3} \mathrm{H}_{4}\right)$ treatment, a procedure which labels terminal galactose or galactosamine residues of the oligosaccharide chains of plasma membrane glycoproteins and glycolipids (Gahmberg \& Hakomori, 1973; Steck \& Dawson, 1974). The second aliquot was radiolabelled by sodium metaperiodate$\mathrm{NaB}^{3} \mathrm{H}_{4}$ treatment to label sialic acid residues of glycoproteins or glycolipids preferentially (Morrell, Van Den Hamer \& Scheinberg, 1966; Van Lenten \& Ashwell, 1971). For these procedures $1 \mathrm{ml}$ aliquots of the sperm suspension were incubated at $37^{\circ} \mathrm{C}$ for $15 \mathrm{~min}$ with $20 \mu \mathrm{l}$ galactose oxidase ( $1 \mathrm{U} / \mu \mathrm{l}$ : Worthington Biochemicals, Freehold, New Jersey, U.S.A.) or with $20 \mu \mathrm{l} 0 \cdot 1 \mathrm{M}$-sodium metaperiodate $\left(\mathrm{NaIO}_{4}\right)$. The suspensions were then centrifuged at $500 \mathrm{~g}$ for $5 \mathrm{~min}$. The pellets were re-suspended with $1 \mathrm{ml} \mathrm{PBS}$ and $20 \mu \mathrm{l}$ sodium boro $\left[{ }^{3} \mathrm{H}\right.$ ]hydride $\left(\mathrm{NaB}^{3} \mathrm{H}_{4}\right.$; $25 \mathrm{mCi} / \mathrm{ml}$ : New England Nuclear, Boston, Massachusetts, U.S.A.) were added and the tubes incubated for $15 \mathrm{~min}$ at $37^{\circ} \mathrm{C}$. After centrifugation at $500 \mathrm{~g}$ for $5 \mathrm{~min}$ the pellets were washed twice by re-suspension with $5 \mathrm{ml}$ PBS followed by centrifugation at $500 \mathrm{~g}$ for $10 \mathrm{~min}$. The final pellets were extracted at room temperature for $1 \mathrm{~h}$ with $250 \mu \mathrm{l}$ of a demembranating solution composed of $1 \%$ sodium dodecyl sulphate (SDS), 1 mM-ethylenediaminetetraacetic acid (EDTA), $10 \%$ sucrose and $10 \mathrm{~mm}$-Tris- $\mathrm{HCl}$ ( $\mathrm{pH} \mathrm{8.0)}$. Non-solubilized components were removed by centrifugation in a microcentrifuge at $8000 \mathrm{~g}$ for $5 \mathrm{~min}$. The supernatant solutions were used for SDS-poly acrylamide gel electrophoresis.

Soluble constituents of seminal plasma were subjected to the same radiolabelling procedures as spermatozoa. The $500 \mathrm{~g}$ supernatant obtained by centrifugation of liquefied semen was diluted to 1-2 $\mathrm{ml}$ with PBS containing $1 \mathrm{~mm}$-phenyl methyl sulphonylfluoride as a protease inhibitor and clarified by centrifugation at $100000 \mathrm{~g}$ for $30 \mathrm{~min}$. Protein concentration in the supernatant was determined by the method of Bradford (1976). Aliquots $(1 \mathrm{ml})$ of the seminal plasma supernatants were incubated with $20 \mu \mathrm{l}$ galactose oxidase $(1 \mathrm{U} / \mu \mathrm{l})$ or $20 \mu \mathrm{l} 0 \cdot 1 \mathrm{M}-\mathrm{NaIO}_{4}$ for $15 \mathrm{~min}$ at $37^{\circ} \mathrm{C}$. Labelled seminal plasma was then dialysed at $4^{\circ} \mathrm{C}$ against several changes of deionized water and freeze-dried or the protein components were precipitated by the addition of 9 volumes of ice-cold acetone followed by incubation on ice for $1 \mathrm{~h}$ and centrifugation at 8000 $\boldsymbol{g}$ for $5 \mathrm{~min}$. This acetone pellet was washed twice with acetone and then dried under nitrogen gas. Both the freeze-dried seminal plasma and the acetone-precipitated seminal plasma were solubilized at $60^{\circ} \mathrm{C}$ in SDS sample buffer composed of $1 \%$ SDS, 1 mM-EDTA, $10 \%$ sucrose, 40 mM-dithiothreitol (DTT) and $10 \mathrm{~mm}$ Tris- $\mathrm{HCl}$ (pH 8.0).

For SDS-polyacrylamide gel electrophoresis the protocol of Fairbanks, Steck \& Wallach (1971) was employed. Before electrophoresis all samples were made $40 \mathrm{~mm}$ in DTT and heated to $100^{\circ} \mathrm{C}$ for $3-5 \mathrm{~min}$. Samples were electrophoresed at $100 \mathrm{~V}$ on $5 \mathrm{~mm} \times 11 \mathrm{~cm}$ tube gels. Gels for scintillation counting contained $N, N^{\prime}$-diallytartardiamide (BioRad Laboratories, Richmond, California, U.S.A.) as the cross-linker. Gels were stained with Coomassie Brilliant Blue $\mathbf{R}$ or sliced into $2 \mathrm{~mm}$ segments for scintillation counting. Gel slices were solubilized with $0.5 \mathrm{ml} 2 \%$ periodic acid. Molecular weights of macromolecular components were estimated by comparing their relative mobilities to the mobility of standard proteins of known molecular weight. 


\section{Results}

Spermatozoa showed incorporation of radioactivity into macromolecular components with both the sodium metaperiodate- $\mathrm{NaB}^{3} \mathrm{H}_{4}$ and galactose oxidase- $\mathrm{NaB}^{3} \mathrm{H}_{4}$ radiolabelling protocols. SDS-polyacrylamide gels revealed two labelled macromolecular components in sodium metaperiodate- $\mathrm{NaB}^{3} \mathrm{H}_{4}$-labelled spermatozoa. The apparent mean molecular weights were 37000 for one component and 25000 for the other (Text-fig. 1). In all samples more counts were incorporated into the component of lower molecular weight. There was also a bipartite peak of radioactivity running close to the tracking dye (Text-fig. 1). The gels of galactose oxidase- $\mathrm{NaB}^{3} \mathrm{H}_{4}$-labelled spermatozoa revealed a single peak of radioactivity for a macromolecule of mean molecular weight 37000 and a peak of radioactivity migrating near the tracking dye front (Text-fig. 1).

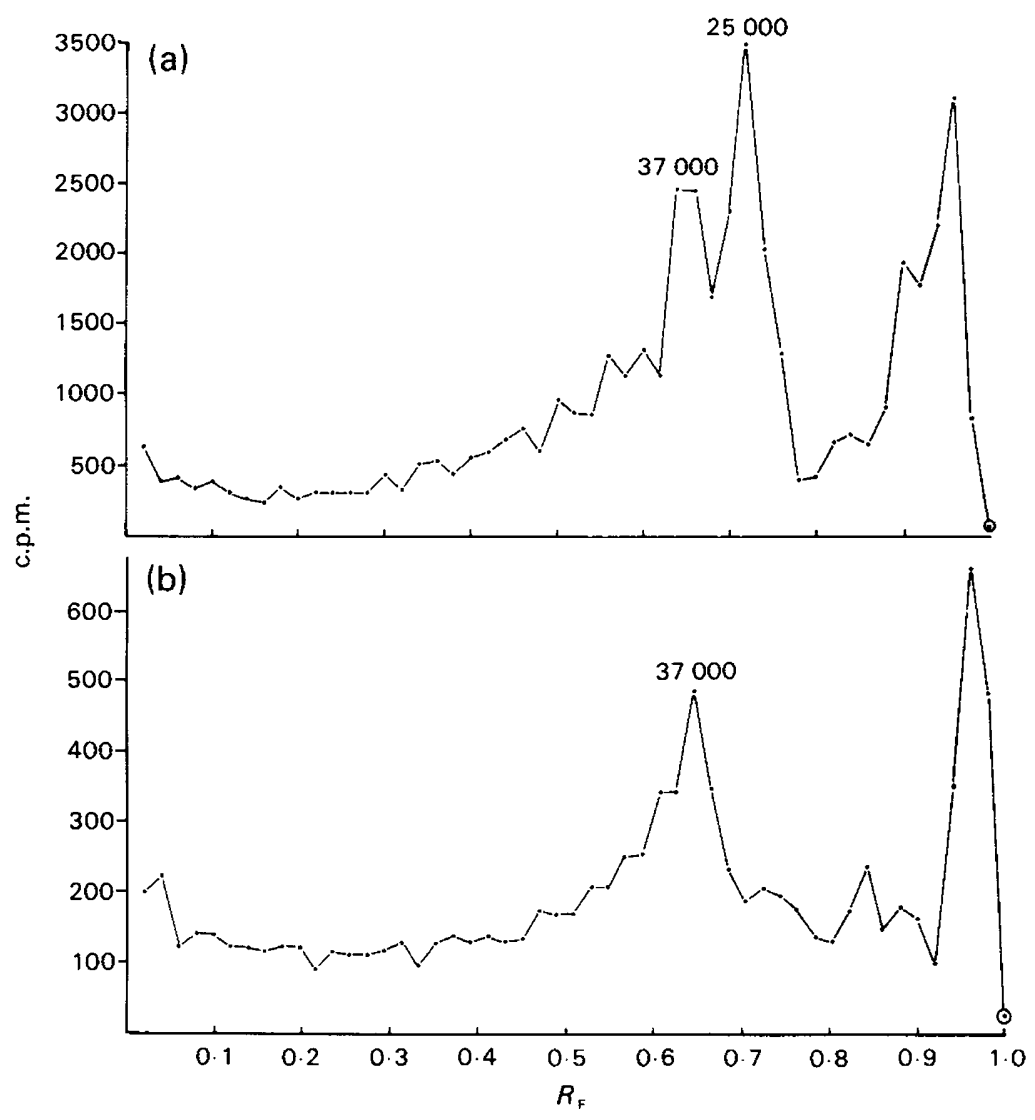

Text-fig. 1. Profiles of radioactivity resolved by SDS-polyacrylamide gel electrophoresis of chimpanzee spermatozoa labelled with (a) $\mathrm{NaIO}_{4}-\mathrm{NaB}^{3} \mathrm{H}_{4}$ and (b) galactose oxidase- $\mathrm{NaB}^{3} \mathrm{H}_{4}$. The mean molecular weight values are indicated.

Macromolecular components of seminal plasma were radiolabelled by both protocols. With the conditions used the incorporations were up to 2700 c.p.m./ $\mu \mathrm{g}$ protein with the $\mathrm{NaIO}_{4}$ probe and up to $5500 \mathrm{c.p} . \mathrm{m} . / \mu \mathrm{g}$ protein with the galactose oxidase probe. SDS-polyacrylamide gels of $\mathrm{NaIO}_{4}-\mathrm{NaB}^{3} \mathrm{H}_{4}$-labelled seminal plasma revealed 3 prominent macromolecular peaks of radioactivity corresponding to molecular weights of 47000,37000 and 19000 (Text-fig. 2). A peak of radioactivity was present near the tracking dye front and a peak was present at the top 


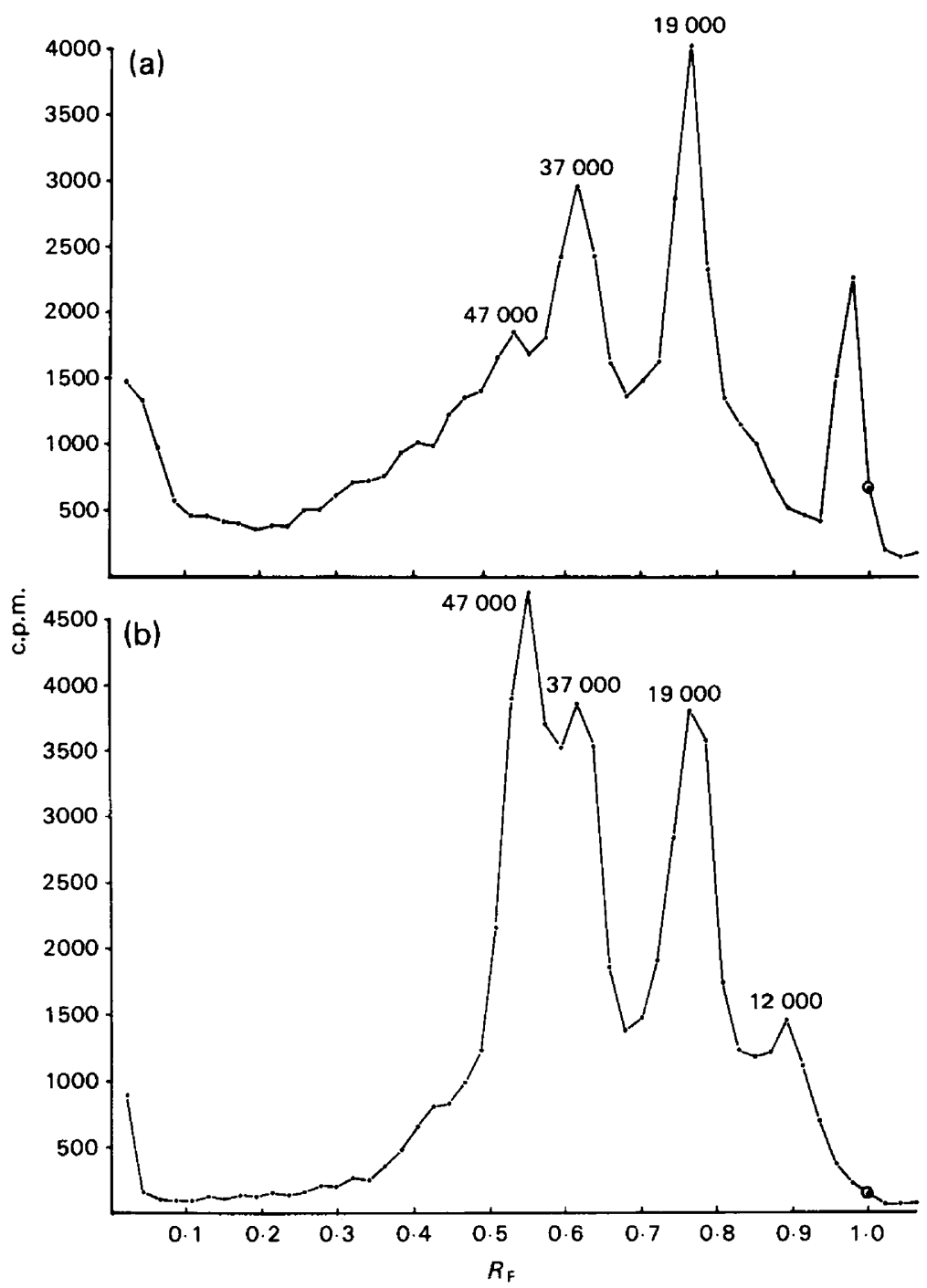

Text-fig. 2. Profiles of radioactivity seen in SDS gels of chimpanzee seminal plasma labelled with (a) $\mathrm{NaIO}_{4}-\mathrm{NaB}^{3} \mathrm{H}_{4}$ or (b) galactose oxidase- $\mathrm{NaB}^{3} \mathrm{H}_{4}$.

of the gel; it is not yet clear whether the latter peak represents a very high molecular weight component or aggregated material.

SDS-polyacrylamide gels of galactose oxidase- $\mathrm{NaB}^{3} \mathrm{H}_{4}$-labelled seminal plasma resolved 4 macromolecular peaks of radioactivity, including components of molecular weights of 47000 , 37000,19000 and 12000 (Text-fig. 2). The mean molecular weight values for the first 3 peaks were identical to those obtained in seminal plasma labelled with $\mathrm{NaIO}_{4}-\mathrm{NaB}^{3} \mathrm{H}_{4}$ but the distribution of radioactivity amongst the peaks was different. There was variation between animals in the relative labelling of the 19000 component by the galactose oxidase probe; usually it was less labelled than the 47000 and 37000 components, but in some samples it was the most heavily labelled component. The basis for this variation is unclear. The fourth peak noted in galactose oxidase-labelled seminal plasma has a mean molecular weight of 12000 and it had the least incorporated label. There was also a radioactive peak at the top of the gel but not one at the front. 
Coomassie blue-stained gels of seminal plasma revealed several bands of molecular weight between 92000 and 10000 (Text-fig. 3). In addition to the presence of well-defined bands all the gels displayed a homogeneous background staining.

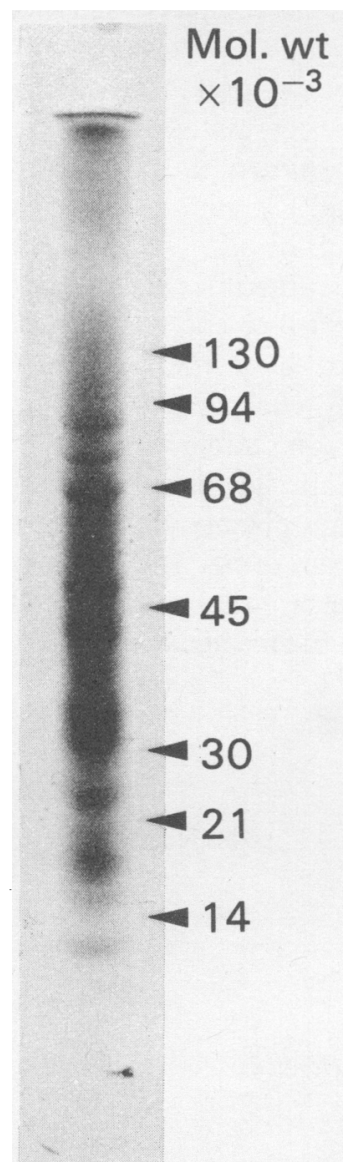

Text-fig. 3. Coomassie blue-stained S $\overline{\mathrm{DS}}$ gel of seminal plasma proteins. The positions of the molecular weight markers are indicated.

\section{Discussion}

The results presented above demonstrate similarities and differences in the glycoprotein components of the sperm surface and seminal plasma. The data indicate that a component of $37000 \mathrm{~mol}$. wt is present on the sperm surface and in seminal plasma. The 37000 components of spermatozoa and seminal plasma were reactive with both radiolabelling protocols, suggesting that they possess multiple or branched oligosaccharide chains some of which possess terminal galactose-like residues while others possess terminal sialic acid residues. The 37000 component of the sperm surface appears to be tightly bound since it is not readily removed by multiple post-labelling washes, but further work is required to establish its identity. A component of molecular weight 37000 has been identified on the rat sperm surface (Olson \& Hamilton, 1978) and a 37000 sialoglycoprotein which is a secretory product of the epididymal epithelium has also been identified in the rat (Lea et al., 1978). Moreover the forward motility protein of bovine seminal plasma also has a subunit molecular weight of 37000 and it, too, is thought to bind to 
the sperm surface (Hoskins, Brandt \& Acott, 1978). The peaks at the tracking dye fronts were probably labelled glycolipids (Steck \& Dawson, 1974; Gahmberg, Häyry \& Andersson, 1976).

Several differences in the labelling pattern of the spermatozoa and seminal plasma were noted. Spermatozoa but not seminal plasma possessed a $25000 \mathrm{~mol}$. wt sialoglycoprotein which reacted with the sodium metaperiodate probe only, while the 47000,19000 and 12000 components of seminal plasma were not present in spermatozoa. However, this result does not preclude a weak interaction between spermatozoa and these seminal plasma components which could have been disrupted by the washing of the cells before and after the labelling protocols.

The 47000,37000 and 19000 components of seminal plasma are probably sialoglycoproteins as they are labelled by the sodium metaperiodate- $\mathrm{NaB}^{3} \mathrm{H}_{4}$ treatment. An interaction of any of the sialoglycoproteins of seminal plasma with the spermatozoon could affect the relative charge at the cell surface and could contribute to the distribution of the anionic sites that have been demonstrated over the surface of primate spermatozoa by electron microscopic studies using positively charged colloidal iron as a marker (Cooper \& Bedford, 1971; Gould, 1977). This would be compatible with data obtained from other species for which a change at the sperm surface in both the distribution and abundance of specific saccharide residues has been demonstrated after ejaculation (Yanagimachi, Noda, Fujimoto \& Nicolson, 1972; Gordon et al., 1975; Nicholson et al., 1977). Further work will be required to see if the individual seminal plasma components interact with specific segments of the sperm surface and to determine how they contribute to the fertilization process.

This work was supported by Public Health Service Grant HD-11816.

\section{References}

Barker, L.D.S. \& Amann, R.P. (1971) Epididymal physiology II. Immunofluorescent analyses of epithelial secretion and absorption, and of bovine sperm maturation. J. Reprod. Fert. 26, 319-332.

Bedford, J.M. (1975) Maturation, transport and fate of spermatozoa in the epididymis. In Handbook of Physiology, Section 7: Endocrinology, Volume V: Male Reproductive System, pp. 303-317. Eds D. W. Hamilton \& R. O. Greep. Am. Physiol. Soc., Washington, D.C.

Bedford, J.M. \& Cooper, G.W. (1978) Membrane fusion events in the fertilization of vertebrate eggs. In Membrane Fusion, pp. 65-125. Eds G. Poste \& G. L. Nicolson. Elsevier/North-Holland Biomedical Press, Amsterdam.

Bradford, M.M. (1976) A rapid and sensitive method for the quantitation of microgram quantities of protein utilizing the principle of protein-dye binding. Analyt. Biochem. 72, 248-254.

Cooper, G.W. \& Bedford, J.M. (1971) Acquisition of surface charge by the plasma membrane of mammalian spermatozoa during epididymal maturation. Anat. Rec. 169, 300-301.

Fairbanks, G., Steck, T.L. \& Wallach, D.F.H. (1971) Electrophoretic analysis of the major polypeptides of the human erythrocyte membrane. Biochemistry, N.Y. 10, 2606-2617.

Gahmberg, C.G. \& Hakomorl, S. (1973) External labelling of cell surface galactose and galactosamine in glycolipid and glycoprotein of human erythrocytes. J. biol. Chem. 248, 4311-4317.

Gahmberg, C.G., Häyry, P. \& Andersson, L.C. (1976)
Characterization of surface glycoproteins of mouse lymphoid cells. J. Cell Biol. 68, 642-653.

Gordon, M., Dandekar, P.V. \& Bartoszewicz, W. (1975) The surface coat of epididymal, ejaculated and capacitated sperm. J. Ultrastruct. Res. 50, 199-207.

Gould, K.G. (1977) Fertility of primate spermatozoa: Application of scanning electron microscopy and energy dispersive $\mathrm{x}$-ray analysis. In Scanning Electron Microscopy, Vol. 11, pp. 333-341. Eds O. Johari \& R. P. Becker. Chicago Press, Chicago.

Hoskins, D.D., Brandt, H. \& Acott, T.S. (1978) Initiation of sperm motility in the mammalian epididymis. Fedn Proc. Fedn Am. Socs exp. Biol. 37, 2534-2542.

Hunter, A.G. (1969) Differentiation of rabbit sperm antigens from those of seminal plasma. J. Reprod. Fert. 20, 413-418.

Killian, G.J. \& Amann, R.P. (1973) Immunoelectrophoretic characterization of fluid and sperm entering and leaving the bovine epididymis. Biol. Reprod. 9 , 489-499.

Lea, O.A., Petrusz, P. \& French, F.S. (1978) Purification and localization of acidic epididymal glycoprotein (AEG): a sperm coating protein secreted by the rat epididymis. Int. J. Androl., Suppl. 2, 592-607.

Morell, A.G., Van Den Hamer, C.J.A. \& Scheinberg, I.H. (1966) Physical and chemical studies on ceruloplasmin. IV. Preparation of radioactive, sialic acid-free ceruloplasmin labelled with tritium on terminal d-galactose residues. J. biol. Chem. 241, 3745-3749.

Nicolson, G.L., Usui, N., Yanagimachi, R., 
Yanagimachi, H. \& Smith, J.R. (1977) Lectinbinding sites on the plasma membranes of rabbit spermatozoa. Changes in surface receptors during epididymal maturation and after ejaculation. $J$. Cell Biol. 74, 950-962.

Olson, G.E. \& Hamilton, D.W. (1978) Characterization of the surface glycoproteins of rat spermatozoa. Biol. Reprod. 19, 26-35.

Orgebin-Crist, M.-C., Danzo, B.J. \& Davies, J. (1975) Endocrine control of the development and maintenance of sperm fertilizing ability in the epididymis. In Handbook of Physiology, Section 7: Endocrinology, Volume V, Male Reproductive System, pp. 319-338. Eds D. W. Hamilton \& R. O. Greep. Am. Physiol. Soc., Washington, D.C.
Steck, T.L. \& Dawson, G. (1974) Topographical distribution of complex carbohydrates in the erythrocyte membrane. J. biol. Chem. 249, 2135-2142.

Van Lenten, L. \& Ashwell, G. (1971) Studies on the chemical and enzymatic modification of glycoproteins. J. biol. Chem. 246, 1889-1894.

Voglmayr, J.K., Fairbanks, G., Jackowitz, M.A. \& Colella, J. (1980) Post-testicular developmental changes in the ram sperm cell surface and their relationship to luminal fluid proteins of the reproductive tract. Biol. Reprod. 22, 655-667.

Yanagimachi, R., Noda, Y.D., Fujimoto, M. \& Nicolson, G.L. (1972) The distribution of negative surface charges on mammalian spermatozoa. Am. J. Anat. $135,497-520$.

Received 14 August 1980 